\title{
Atuação fisioterapêutica nos pacientes com sequelas de meningite: Um estudo de revisão
}

\author{
Physiotherapeutic performance in patients with squeals of meningitis: \\ A Review Study
}

\begin{abstract}
Karla Camila Correia da Silva ${ }^{1}$, Janaína Oliveira da Silva ${ }^{2}$, Thatiely Claudia Liandro ${ }^{3}$
\end{abstract}

\section{RESUMO}

Introdução: A meningite consiste em um processo inflamatório das meninges, que são membranas que envolvem o cérebro e a medula espinhal. Esta pode ser causada por diversos agentes infecciosos, como bactérias, vírus, parasitas e fungos, ou também por processos não infecciosos. Trata-se de uma grave infecção em razão do seu risco potencial de complicações e sequelas em longo prazo da doença e pela sua gravidade. Objetivo: Discorrer sobre a atuação fisioterapêutica nos pacientes com sequelas de meningite. Materiais e Métodos: Foi realizada uma revisão da literatura, onde foram coletados os resultados dos principais estudos contidos no portal de periódicos da CAPES, na Scielo e no LILACS. Discussão: São apresentados estudos que completam a caracterização da doença, do tratamento medicamentoso e da importância do tratamento fisioterapêutico na evolução das sequelas apresentadas. Conclusão: Por intermédio do levantamento bibliográfico, pode-se afirmar que há evidências suficientes na literatura que possibilitem indicar a suma importância da atuação do fisioterapeuta na promoção da qualidade de vida do paciente em tratamento de sequelas decorrentes da meningite.

Descritores: meningite, encefalite, reabilitação, fisioterapia.

\section{ABSTRACT}

Introduction: Meningitis is an inflammatory process of meninges, which are membranes that surround the brain and spinal cord. This can be caused by various infectious agents such as bacteria, viruses, parasites and fungi, or also by non-infectious processes. It is a serious infection because of its potential risk of long-term complications and sequels of the disease and its severity. Objective: To discuss the physiotherapeutic performance in patients with sequels of meningitis. Methodology: A literature review was performed, collecting the results of the main studies contained in the CAPES journal portal, Scielo and LILACS. Discussion: Studies are presented that complete the characterization of the disease, drug treatment and the importance of physiotherapeutic treatment in the evolution of the sequels presented. Conclusion: Through the bibliographic survey, it can be stated that there is sufficient evidence in the literature to indicate the paramount importance of the role of the physical therapist in promoting the quality of life of patients undergoing treatment for meningitis sequels.

Keywords: meningitis, encephalitis, rehabilitation, physical therapy.
${ }^{1}$ Fisioterapeuta (UNIRG/TO). Mestranda em Bioengenharia com ênfase na Saúde pela Universidade Brasil. Especialista em Fisioterapia Cardiopulmonar e Terapia Intensiva (Universidade São Marcos/ Ceafi). Docente do curso de fisioterapia do Instituto Educacional Santa Catarina Faculdade Guaraí -IESC/FAG. Email:

karlacamilac@yahoo.com.br

${ }^{2}$ Graduanda em Fisioterapia pelo Instituto Educacional Santa Catarina (IESC/FAG) de GuaraTO. Email:

janainaosfisio@gmail.com

${ }^{3}$ Graduanda em Fisioterapia pelo Instituto Educacional Santa

Catarina (IESC/FAG) de Guara -

TO. Email: thaty_cl@outlook.com 


\section{INTRODUÇÂOO}

No Brasil, a meningite é considerada uma doença endêmica, deste modo, casos da doença são esperados ao longo de todo o ano, com a ocorrência de surtos e epidemias ocasionais. A ocorrência das meningites bacterianas é mais comum no inverno e, das virais, no verão'.

A distribuição das meningites é mundial e sua expressão epidemiológica depende de fatores como: agente etiológico, aglomerados populacionais e faixa etária acometida. A notificação é imediata a simples suspeita devido a sua morbimortalidade².

A meningite é um processo inflamatório das meninges, membranas que envolvem o cérebro e a medula espinhal. Esta pode ser causada por diversos agentes infecciosos, como bactérias, vírus, parasitas e fungos, ou também por processos não infecciosos. Sua ocorrência pode ser ainda em virtude de causas sistêmicas, como leucemias, linfomas, sarcoidose, neoplasias tóxicas, irritação química e pós-vacinas"

Caracterizada como uma grave infecção em detrimento do seu risco potencial de complicações e sequelas em longo prazo da doença e a sua gravidade, a meningite depende do microrganismo causador, bem como de fatores relacionados com o hospedeiro ${ }^{3}$.

Sob a ótica da saúde pública, as meningites bacterianas e virais são consideradas as mais importantes, devido a sua magnitude, a capacidade de ocasionar surtos e, no caso da meningite bacteriana, a gravidade dos casos, uma vez que, apenas as meningites bacterianas e virais são contagiosas'1.

O principal reservatório da doença é o homem, com a forma pulmonar bacilífera de maior importância epidemiológica. No caso da meningite tuberculosa, outros animais, em especial o gado bovino, acabam sendo reservatório da doença ${ }^{4}$. Uma das maneiras mais eficazes de prevenir e controlar as infecções por meningite é a vacinação, uma vez que a mesma já se encontra disponível na rede pública de vacinação, porém, somente para alguns tipos específicos de infecções dessa epidemiologia.

Uma vez contraída a doença, há o tratamento medicamentoso, no qual, devido às sequelas que geralmente ocorrem em detrimento da intensidade desta infecção, deve-se incorporar o tratamento fisioterapêutico como forma de promover melhorias na recuperação do paciente, minimizando os efeitos trazidos pela meningite.

As sequelas mais comuns causadas por esta doença são: perda de audição parcial ou total; epilepsia; problemas de memória e concentração; dificuldade de aprendizagem, 
tanto em crianças quanto em adultos; perda de visão parcial ou total; atraso no desenvolvimento motor, com dificuldades para andar e se equilibrar; paralisia de um lado do corpo ou dos dois; amputação de membros, quando necessário para impedir a disseminação da doença para o restante do corpo; artrite e problemas nos ossos; problemas nos rins; dificuldade para dormir e incontinência urinária ${ }^{5}$.

Diante disto o presente artigo tem por objetivo discorrer sobre a atuação fisioterapêutica nos pacientes com sequelas de meningite, sendo consultados artigos por meio de portais de periódicos disponíveis em meio eletrônico, tais como Scielo, Capes, Lilacs.

\section{MATERIAIS E METODOS}

A pesquisa foi elaborada por meio de artigos científicos online na área da saúde. Foram incluídas publicações do período de 2006 a 2018 em línguas portuguesa, espanhola e inglesa. O período de elaboração do protocolo se estendeu de janeiro a setembro de 2018. Foram exclusas referências que não apresentavam relação com a temática e com o ano de publicação inferior a 2006.

Para buscas nas bases de dados foram utilizados os descritores: meningite, tipos de meningite, tratamento de meningite, fisioterapia e meningite. Com o fito de ordenar e descrever as informações contidas nas fontes foi realizada uma leitura analítica como forma de possibilitar a obtenção de respostas ao tema da pesquisa.Ao todo, foram identificados 10 (dez) estudos, sendo consultados por meio de portais de periódicos disponíveis em meio eletrônico, tais como Scielo, Capes, Lilacs.

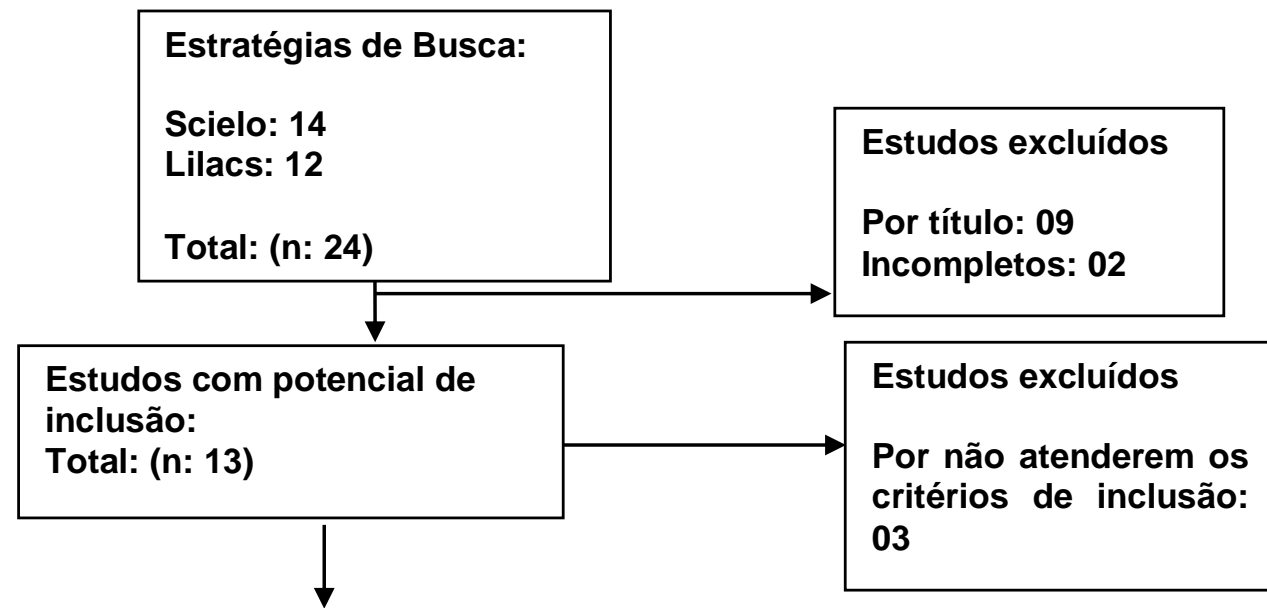

Estudos incluídos na revisão Total: (n: 10) 


\section{DESENVOLVIMENTO}

A palavra meningite provém do latim moderno "meninga" e do grego "menix", que significa membrana, sendo classificada como uma infecção grave das membranas que revestem o encéfalo e medula espinhal, causada por diversos agentes e condições clínicas. Tal enfermidade representa um importante desafio para saúde pública devido às altas taxas de morbimortalidade e graves sequelas neurológicas, especialmente em crianças menores que cinco anos ${ }^{(6,7)}$.

O prognóstico das meningites depende de fatores como: o organismo causador, a gravidade da infecção e da doença e o tratamento adequado. Mediante a ocorrência de um quadro clínico agudo fulminante pode ser observado danos suprarrenais, colapso circulatório e hemorragias generalizadas. As complicações incluem comprometimento visual, surdez, convulsões, paralisia, hidrocefalia e choque séptico ${ }^{8}$.

As manifestações sintomáticas mais frequentes da meningite são a cefaleia, a febre alta, o vômito, a rigidez em região cervical e o rebaixamento do nível de consciência. A variação da taxa de mortalidade é ampla, desde $2 \%$ em crianças até 20 a $30 \%$ em neonatos e adultos. Grande número dos casos não fatais são associados a sequelas neurológicas ${ }^{9}$.

A irritação meníngea associa-se aos seguintes teste ${ }^{10}$.

- Teste de Kernig: resposta em flexão da articulação do joelho, quando a coxa é colocada em certo grau de flexão, relativamente ao tronco. Há duas formas de se pesquisar esse teste: - paciente em decúbito dorsal: eleva-se o tronco, fletindo-o sobre o quadril; há flexão da perna sobre a coxa e desta sobre o quadril; - paciente em decúbito dorsal: eleva-se o membro inferior em extensão, fletindo-o sobre o quadril; após pequena angulação, há flexão da perna sobre a coxa. Essa variante chama-se, também, manobra de Laségue.

- Teste de Brudzinski: flexão involuntária da perna sobre a coxa e desta sobre a quadril, ao se tentar fletir a cabeça do paciente.

No Brasil, no ano de 2016 , foram confirmados 14.867 casos de meningite, dos quais $22 \%$ corresponderam à meningite bacteriana ${ }^{10}$. Dados mais recentes concernentes ao estado da Bahia, até a semana epidemiológica 27 (ocorrida em 09 de julho de 2016), apontaram um total de 189 casos de meningite, dos quais $27 \%$ foram atribuídos à tipologia bacteriana ${ }^{11}$.

A meningite bacteriana é a forma mais grave. Esta meningite costuma ser causada pelas bactérias Streptococcus pneumoniae, Haemophilus influenzae ou Neisseria 
mengitidis. Outras bactérias, como a Listeria monocytogenes, Staphylococcus aureus e Streptococcus do grupo B também podem ser a causa, mas não são tão comuns como as três primeiras citadas ${ }^{12}$. Este tipo representa um problema de saúde pública, por ser uma emergência médica, que requer diagnóstico e tratamento imediato. A meningite meningocócica é uma infecção bacteriana aguda, rapidamente fatal, causada pela Neisseria meningitidis. Esta bactéria pode causar inflamação nas membranas que revestem o sistema nervoso central (meningite) e infecção generalizada (meningococcemia) ${ }^{13}$.

A meningite viral é menos agressiva que a bacteriana, com taxa de mortalidade inferior e com resolução espontânea, sem necessidade de tratamento específico, na maioria dos casos. Sendo identificada por um quadro clínico de alteração neurológica, que, geralmente, progride de maneira benigna. Os casos podem ocorrer isoladamente, embora o aglomerado de casos (surtos) seja comum. Indivíduos de todas as idades se encontram suscetíveis, porém a faixa etária de maior risco é a de menores de cinco anos. Aproximadamente $85 \%$ dos casos são devido ao grupo dos Enterovírus, dentre os quais se destacam os Poliovírus, os Echovírus e os Coxsackievírus dos grupos A e B 1,2. O manejo deve ser adequado para cada etiologia ${ }^{(12,14)}$.

Os agentes etiológicos mais frequentes são ${ }^{14}$ :

- No grupo de Vírus RNA - Enterovírus; Arbovírus; Vírus do sarampo; Vírus da caxumba; Vírus da Coriomeningite; Linfocitária (arenavírus); HIV;

- No grupo de Vírus DNA - Adenovírus; Herpes simples tipo1 e 2; Varicela zoster, Epstein Barr, Citomegalovírus.

O tipo de meningite parasitária é causado por Naegleria fowleri, um tipo de parasita encontrado nas águas doces e temperadas (lagos, lagoas, etc). Este parasita pode causar meningoencefalite primária, que é um tipo de infecção que destrói o tecido cerebral progressivamente ${ }^{15}$.

A meningite fúngica é mais rara que as meningites virais e bacterianas, sendo mais comum em pacientes imunossuprimidos, como em casos de AIDS e câncer, por exemplo. Pode se tornar crônica devido ao processo inflamatório contínuo das meninges (membrana que envolve o cérebro e a medula espinhal), podendo causar sérias complicações, como hidrocefalia e interrupção do fluxo sanguíneo cerebral.

Uma das causas menos difundidas, provavelmente em razão da menor importância epidemiológica, é a meningite eosinofílica. Este tipo de infecção é identificado por sintomas que apontam, além do envolvimento do sistema nervoso central, a presença de eosinófilos 
no líquido cefalorraquidiano superior a 10 células por $\mathrm{ml}$ ou um total de eosinófilos que corresponde a $10 \%$ ou mais do total de leucócitos presentes ${ }^{16}$.

Outros fatores de risco para desenvolver meningite são: desnutrição, imunossupressão (radioterapia, quimioterapia, tratamento com corticoide prolongado) e traumatismos do sistema nervoso central. Além disso, outros processos infecciosos bacterianos como bacteremia (pneumonia, empiema, osteomielite e endocardite), sinusite, otite média, encefalite, mielite e abscesso cerebral ${ }^{17}$.

Fatores peculiares do hospedeiro como condição imunológica e faixa etária podem intervir na prevalência destas infecções. A influência dos mesmos determina a população de risco como sendo crianças menores de cinco anos de idade, idosos com idade superior aos 60 anos e pacientes imunocomprometidos ${ }^{2}$.

A transmissão da meningite é de pessoa a pessoa, por meios das vias respiratórias ou por gotículas e secreções da nasofaringe, sendo assim há a necessidade de um contato íntimo com indivíduo infectado ou contato direto com secreções respiratórias do paciente. Normalmente o período de incubação é de 2 a 10 dias, em média 3 a 4 dias, mas isso varia de acordo com o agente etiológico que está causando a doença ${ }^{18}$.

Essa doença pode deixar sequelas bastante graves como, perda total ou parcial de audição, tetraparesia, déficit motores severos, convulsões e outros, podendo, inclusive, conduzir à morte ${ }^{29}$. Característica importante que revela a importância da prevenção de tal enfermidade, e nos casos de contágio o rápido e eficaz tratamento.

\section{Tratamento Medicamentoso}

A causa da meningite diagnosticada é imprescindível na determinação do tratamento, variando desde o trato para alívio dos sintomas (nas meningites virais e traumáticas) até a antibioticoterapia (nas meningites bacterianas, fúngicas e eosinofílicas). No tocante a meningite bacteriana, o tratamento com antibiótico deve ser instituído tão logo seja possível, preferencialmente logo após a punção lombar e a coleta de sangue para hemocultura. $\mathrm{O}$ uso de antibiótico deve ser associado a outros tipos de tratamento de suporte, como reposição de líquidos, fisioterapia e cuidadosa assistência ${ }^{10}$.

O tratamento das meningites virais é de suporte: antitérmicos como dipirona, antieméticos (metoclopramida), cabeceira elevada a $30^{\circ}$. Se o paciente estiver sonolento 
ou confuso ou com dificuldade de deglutição, deverá ser mantida sonda nasogástrica para hidratação adequada e evitar broncoaspiração ${ }^{14}$.

A precocidade do tratamento e diagnóstico são fatores importantes para o prognóstico satisfatório das meningites, pois quanto mais rápido o atendimento médico, maiores as chances de uma boa recuperação do paciente, reduzindo o risco de óbito ou sequelas (paralisia dos membros, perda auditiva, perda da visão, etc.) ${ }^{10}$.

\section{Tratamento Fisioterapêutico}

O exercício terapêutico é considerado um elemento central na maioria dos planos de assistência da fisioterapia, com a finalidade de aprimorar a funcionalidade física e reduzir incapacidades. Inclui uma gama de atividades que previnem complicações como encurtamentos, fraquezas musculares e deformidades osteoarticulares e reduzem a utilização dos recursos da assistência de saúde durante a hospitalização ou após uma cirurgia. Estes exercícios aprimoram ou preservam a função física ou o estado de saúde dos indivíduos sadios e previnem ou minimizam as suas futuras deficiências, a perda funcional ou a incapacidade ${ }^{21}$.

A atuação fisioterapêutica deve ser individualizada, variando de acordo com as necessidades específicas de cada paciente, onde a mesma irá influenciar na conduta a ser realizada, estabelecendo as prioridades do tratamento. Existem diversos tipos de técnicas de tratamento fisioterapêutico com o objetivo de manter a resistência e a força, bem como a amplitude de movimento passiva e ativa. A facilitação e inibição neuromuscular, o posicionamento e a mobilização são modalidades viáveis para normalizar o tônus muscular conforme necessário. O treinamento da marcha, quando possível, o uso de assistência para andar, o treinamento em planejamento motor, bem como exercícios de equilíbrio e a resistência ${ }^{22}$.

A fisioterapia respiratória pode definir-se como uma especialidade que utiliza técnicas de avaliação e tratamento que buscam prevenir, reverter ou minimizar disfunções ventilatórias, promovendo a máxima funcionalidade e qualidade de vida dos pacientes ${ }^{23}$.

A ideia original da fisioterapia está inserida como uma área da saúde que estuda, previne e trata distúrbios cinético-funcionais decorrentes de alterações em órgãos e sistemas do corpo humano, podendo ser incluído nessas alterações. O perfil do fisioterapeuta está se alterando, por meio do qual a habilidade clínica do mesmo deve 
envolver a capacidade de gerir, avaliar, observar, prescrever, tratar e se comunicar ${ }^{24}$.

Considerando as sequelas apontadas em detrimento da meningite, foram efetivadas buscas por estudos que retratassem a atuação fisioterapêutica no tratamento das mesmas, conforme síntese apresentada no quadro 1.

Quadro 1 - Síntese dos estudos acerca da atuação fisioterapêutica no tratamento de sequelas da meningite

\begin{tabular}{|c|c|c|}
\hline Autor & Ano & Objetivo \\
\hline $\begin{array}{l}\text { Tako, Karine } \\
\text { Vaccaro; } \\
\text { Zambianchi, }\end{array}$ & 2006 & $\begin{array}{l}\text { Influência da hidroterapia em } \\
\text { pacientes portadores de } \\
\text { sequelas da meningite }\end{array}$ \\
\hline
\end{tabular}

Os resultados indicaram que a hidroterapia é benéfica, devido aos seus efeitos fisiológicos com o paciente imerso na água aquecida, no qual promoveu relaxamento muscular, redução do espasmo muscular, aumento da facilidade do movimento articular dentro da água, além de promover um bem estar para o paciente, melhorando o estado psicológico, promovendo prazeres com os movimentos e elevando a confiança e a autoestima.

\begin{tabular}{|c|c|c|}
\hline $\begin{array}{l}\text { Auriema, } \\
\text { Eskel.; Péia } \\
\text { Beatriz F. Dereira, } \\
\text { Moraes.; } \\
\text { Santana, Paulo } \\
\text { Sérgio Da S }\end{array}$ & 2007 & $\begin{array}{l}\text { Atuação da fisioterapia em um } \\
\text { paciente com quadro agudo de } \\
\text { meningomieloencefalite } \\
\text { bacteriana }\end{array}$ \\
\hline $\begin{array}{l}\text { Girão, Bruna Dias } \\
\text { Sousa et al }\end{array}$ & 2008 & $\begin{array}{l}\text { A importância da fisioterapia } \\
\text { em um paciente sequelado de } \\
\text { meningite criptocócica: estudo } \\
\text { de caso }\end{array}$ \\
\hline
\end{tabular}

Rocha, Monike 2008 Atuação da fisioterapia no Keuly et al paciente relato de caso

\begin{tabular}{ll}
\hline Magalhães, 2011 & Efetividade da fisioterapia em \\
Clarice Bento de & um paciente pós-transplante \\
Araújo et al & hepático com diagnóstico de \\
& $\begin{array}{l}\text { meningite criptocócica: relato } \\
\text { de caso }\end{array}$
\end{tabular}

Gavim, Aline de 2012 A influência da avaliação Oliveira et al fisioterapêutica na reabilitação neurológica Meningoencefalite criptocócica:

Durante todo o período de internação do paciente, a fisioterapia respiratória e motora mostrou-se atuante e eficaz, através das manobras e as intervenções que auxiliaram na melhora clínica do paciente, bem como na retirada da TQT e oclusão da mesma.

O estudo mostrou a importância da fisioterapia diária dentro dos hospitais possibilitando melhoria da qualidade de vida dos pacientes e diminuindo o tempo de hospitalização

O paciente apresentou melhora na função motora, porém a função respiratória permaneceu um pouco inalterada, pois o mesmo apresentava-se bastante largado no leito restringindo assim a expansibilidade pulmonar.

O tratamento proposto trouxe benefícios à paciente, resultando na regressão do quadro de dispneia, melhora do derrame pleural e da força muscular, bem como do bem-estar geral restabelecendo sua integridade física e psicológica em um curto intervalo de tempo.

Conclui-se que a avaliação fisioterapêutica influencia diretamente na reabilitação de pacientes acometidos por doenças do sistema nervoso e busca recuperar a capacidade de realizar as tarefas diárias, para que o indivíduo se torne o mais independente possível e sempre respeitando suas limitações.

José, Anderson et 2013 Avaliar os efeitos da fisioterapia al no desmame da ventilação mecânica.
Os dados obtidos no estudo permitiram aferir que a atuação da fisioterapia no desmame da VM esteve associada ao aumento do número de sucessos no desmame, 


\begin{tabular}{|c|c|c|c|}
\hline $\begin{array}{l}\text { Schneider, } \\
\text { Viviana } \\
\text { Furlanetto } \\
\text { Manduca et al }\end{array}$ & 2017 & $\begin{array}{l}\text { Atuação interdisciplinar em um } \\
\text { paciente com déficit perceptual: } \\
\text { relato de uma experiência }\end{array}$ & $\begin{array}{l}\text { A atuação interdisciplinar da fisioterapia e } \\
\text { psicologia promoveu resultados positivos na } \\
\text { reabilitação do paciente relatado. }\end{array}$ \\
\hline $\begin{array}{l}\text { Silveira, Jêinifer; } \\
\text { Poletto, Patricia; } \\
\text { Santos, Marilucia } \\
\text { Vieira dos }\end{array}$ & 2017 & $\begin{array}{l}\text { Intervenção hidroterapêutica } \\
\text { em paciente com paresia de } \\
\text { Mmii por meningite tuberculosa } \\
\text { e fúngica }\end{array}$ & $\begin{array}{l}\text { Percebeu-se melhora na normalização de } \\
\text { tônus muscular em curto prazo e diminuição } \\
\text { visual da escoliose podendo perceber } \\
\text { tamanho benefício da hidrocinesioterapia } \\
\text { como recurso de reabilitação }\end{array}$ \\
\hline $\begin{array}{lr}\text { Silva, } & \text { Carla } \\
\text { Marcela } & \text { Soares } \\
\text { da et al } & \end{array}$ & 2018 & $\begin{array}{l}\text { A importância da fisioterapia } \\
\text { respiratória na unidade de } \\
\text { terapia intensiva em recém- } \\
\text { nascidos }\end{array}$ & $\begin{array}{l}\text { O profissional da fisioterapia que auxilia na } \\
\text { diminuição da mortalidade dos recém- } \\
\text { nascidos, constatando-se que desempenha } \\
\text { um papel fundamental nas UTI's neonatais } \\
\text { promovendo uma melhor qualidade de vida } \\
\text { aos recém-nascidos para que possam ter } \\
\text { uma alta precoce. }\end{array}$ \\
\hline
\end{tabular}

diminuição do tempo de desmame, de duração da VM e de internação na UTI. Não foram encontradas diferenças no tempo de internação hospitalar e na mortalidade.

No que tange ao estudo apresentado acerca dos neonatos, a meningite consta entre as principais doenças que conduzem a um quadro clínico de difícil tratamento, acarretando na necessidade de internação na unidade de terapia intensiva. Sendo que, na unidade de terapia intensiva neonatal, o fisioterapeuta possui um papel substancial no tratamento e adoção dos cuidados com o recém-nascido. Cabe a este profissional promover melhorias e manter a sobrevida dos recém-nascidos contribuindo para a redução de possíveis complicações ${ }^{25}$.

O acompanhamento fisioterapêutico destes $\mathrm{RN}$ de risco proporciona uma estabilidade de variáveis hemodinâmicas, como frequência cardíaca, manutenção funcional da circulação cerebral e, secundariamente, mantém as vias aéreas livres e minimiza as complicações a que estes neonatos são susceptíveis durante o período de internação ${ }^{26}$.

A equipe integrante da UTI neonatal tem reconhecido cada vez mais a importância do fisioterapeuta dentro destas unidades, pois desencadeiam um papel diferenciado na manutenção da estabilidade e melhora das condições fisiológicas do recém-nascido de alto risco 26 .

No estudo abordando a influência da fisioterapia no desmame ventilação mecânica, por meio de estudo de caso no qual havia um diagnóstico de meningite, foi possível demonstrar que, com duas sessões diárias de 40 minutos, utilizando técnicas de compressão brusca no tórax, hiperinsuflação manual, aspiração traqueal e de vias aéreas superiores, exercícios passivos e ativos assistidos, acompanhamento e condução do desmame da ventilação mecânica, o tratamento fisioterapêutico contribuiu com a 
diminuição do tempo de desmame, de duração da ventilação mecânica e da internação na unidade de terapia intensiva ${ }^{27}$.

No estudo de caso com paciente com pós-transplante hepático com diagnóstico de meningite criptocócica, o tratamento consistiu de exercícios diafragmáticos, exercícios em tempos, soluços inspiratórios, manobras de compressão e descompressão e EPAP (Pressão Positiva Expiratória nas Vias Respiratórias) com PEEP (Pressão Positiva Expiratória no Final da Expiração) de 12 e exercícios ativos para membros superiores e inferiores. Cada atendimento fisioterápico perfazia 40 minutos de duração sendo realizados, no total, 30 atendimentos com avaliação no início e no final do tratamento. Após 30 dias de atendimento fisioterápico, a paciente apresentou melhora da dispnéia, ausência de tosse e eliminação do derrame pleural. Houve evolução da força muscular e redução significativa do edema, bem como promoção do bem estar do paciente ${ }^{23}$.

Em um estudo de caso de um paciente com quadro agudo de meningomieloencefalite bacteriana, mostrou-se que a fisioterapia respiratória e motora se apresentou atuante e eficaz. Uma vez que, o paciente teve acompanhamento assistencial da fisioterapia, com manobras de expansão pulmonar (MEP), vibrocompressão (MVC), tapotagem (TP), compressão e descompressão torácica (MCD), estímulo proprioceptivo diafragmático (EPD), Bag Squeezing (MBS), aspiração de cânula orotraqueal (ASP COT), aspiração da TQT (ASP TQT), vias aéreas superiores (VAS), treinamento de músculos respiratórios com trigger do ventilador mecânico (TMR), cinesioterapia motora com exercícios passivos de membros superiores (MMSS) e membros inferiores (MMII), alongamentos globais, treinamento de força muscular (TFM), estimulação elétrica funcional (FES). Concluindo que, com a devida assistência da fisioterapia desde o primeiro dia de internação na UTI, as manobras respiratórias, juntamente com a cinesioterapia no leito foram de extrema importância e imprescindíveis para a melhora do paciente internado ${ }^{28}$.

No estudo de caso com paciente de 10 anos diagnosticado com paresia de MMII por meningite tuberculosa e fúngica, o tratamento visou à normalização do tônus muscular através do método Watsu, fortalecimento da musculatura abdominal, dos extensores da coluna e dos MMSS através de exercícios hidrocinesioterapêuticos, método Bad Ragaz e Hallwick, alongamento da região lateral de tronco esquerdo, e estimulação da posição ortostática ${ }^{29}$.

Considerada como uma estratégia terapêutica, a fisioterapia aquática é fundamentada na apropriação e utilização dos efeitos provenientes da imersão do corpo 
com o intuito de adquirir, manter ou melhorar a capacidade funcional. Consoantes evidências científicas, os benefícios da prática da hidroterapia são amplos e diversos, podendo variar desde o desenvolvimento das capacidades psicomotoras até a melhora da marcha e funcionalidade ${ }^{30}$.

A técnica de agregar os exercícios aquáticos com os terrestres promove a execução de movimentos com amplitudes e padrões diferenciados, viabilizando a recuperação cinético-funcional de forma mais completa e precoce ${ }^{31}$.

No estudo no qual foi analisado um caso com um paciente de sexo masculino, com 12 anos de idade, apresentando seqüelas de meningite, incluindo déficit de visão e audição, alterações cognitivas, afasia e tetraparesia, o paciente foi submetido a uma avaliação fisioterapêutica, na qual foi possível identificar o tônus, sendo classificado como uma hipertonia (espasticidade) em membros superiores e membros inferiores, a força muscular não foi possível avaliar, e a amplitude de movimento restrita devido ao seu quadro motor. De acordo com alterações vistas, os objetivos do tratamento fisioterapêutico a serem implantados foram: melhorar a ventilação pulmonar, normalizar tônus dos membros, promover alongamentos, melhorar alinhamento e estabilidade do tronco, estimular reações de equilíbrio e promover descarga de peso ${ }^{9}$.

No supracitado estudo de caso, foram utilizadas, em piscina aquecida, técnicas em de relaxamento, mobilizações e alongamentos, deslizamento superficial em supino, compressão e descompressão torácica, tapping diafragmático e treino de equilíbrio de tronco com paciente sentado sofrendo deslocamentos, brinquedos para estimular a busca/preensão, motricidade e sistema visual. Sendo efetivadas quatro sessões de hidroterapia uma vez por semana com a duração de 45 minutos cada. Aferindo-se a redução da espasticidade com o corpo imerso na água, e uma melhora psicológica para o paciente ${ }^{9}$.

Outro estudo de caso observou tratamento de paciente que, em detrimento da meningite, apresentava déficit perceptual, marcha independente em terrenos regulares e ambientes conhecidos, marcha com auxílio de terceiros em ambientes novos e irregulares, ataxia em membros superiores, mais intensa em membro esquerdo, tremores de ação, boa amplitude de movimentos e força muscular, déficit de equilíbrio estático e dinâmico. $\mathrm{O}$ tratamento consistiu em duas sessões semanais de fisioterapia, uma aquática e outro no solo, e uma sessão de atendimento psicológico, desafiando o paciente a resolver problemas com relação ao seu planejamento motor, trabalhando sua atenção ao obstáculo, tentando 
elaborar uma estratégia motora e aprimorando assim seu equilíbrio, controle de core e atividade motora ${ }^{32}$.

Cabe enfatizar o potencial do atendimento interdisciplinar, que permite que um profissional acompanhe o trabalho do outro. Sendo uma oportunidade para que ocorra o aprendizado sobre áreas de distintos saberes. As decisões quanto às intervenções terapêuticas são tomadas em conjunto, levando em conta todos os aspectos do indivíduo, fortalecendo dessa forma as tomadas de decisão ${ }^{32}$.

\section{CONSIDERAÇOES FINAIS}

Mediante os estudos avaliados, nota-se que há evidências suficientes na literatura que possibilitem indicar a suma importância da atuação do fisioterapeuta na promoção da qualidade de vida do paciente, por meio da utilização de técnicas que possibilitem melhorias e tratamento das sequelas desencadeadas em razão da meningite.

A inserção da fisioterapia no tratamento multidisciplinar é vital para que haja uma melhora na capacidade funcional e bem-estar do paciente. Os resultados do tratamento englobam a evolução da capacidade motora com exercícios de fortalecimento muscular, diagonais de facilitação neuromuscular proprioceptiva e exercícios proprioceptivos. Além de melhora do processo respiratório, que também deve constar no plano de tratamento do fisioterapeuta. É imprescindível a realização de uma avaliação criteriosa, salientando as condições gerais de cada paciente, as condições do ambiente e os recursos fisioterapêuticos disponíveis, que viabilizarão a adoção da conduta apropriada para o paciente.

\section{REFERENCIAS}

1. MS - Portal Ministério da Saúde. Meningites, 2017. Disponível:<http://portalms.saude.gov.br/saude-de-az/meningites>. Acesso em: 20/07/2018.

2. Guia de Vigilância Epidemiológica 7. Ed. Normas e manuais técnicos. Brasília, 2009. Cad.12. Disponível em: <http://bvsms.saude.gov.br/bvs/publicacoes/guia_vigilancia_epidemiologica_7ed.pdf.>. Acesso em 20 jun 2018

3. Ferreira M, Mendes C, Janeiro P, Conde M, Aguiar T, Brito MJ. Factores de risco para complicações e sequelas de meningites bacterianas. ActaPediátrica Portuguesa, 2009, 40(6), pp 257-261.

4. SVS -MS- Secretaria de Vigilância em Saúde, Mato Grosso do Sul. Meningites. Guia de Vigilância Epidemiológica | Caderno 12. 2012. Acesso em: 20/07/2018. 
DOI: 10.18606/2318-1419/amazonia.sci.health.v7n3p48-61 Revista Amazônia: Science \& Health

2019, Vol. 7, № 3 .

ISSN: 2318-1419
Silva KCC. Silva JO. Liandro TC.

Atuação fisioterapêutica nos pacientes com sequelas de meningite: Um estudo de revisão.

5. Frazão A. Saiba quais são as Sequelas da Meningite. 2016.

6. Emmerick ICM, Campos MR, Schramm JMA, Silva RS, Costa MFS. Estimativas corrigidas de casos de meningite,Brasil 2008-2009. Epidemiol. Serv. Saúde. Brasília, v. 23, n. 2, p. 215-226, 2014.

7. Silva KRO, Alves MM, Nunes R, Pereira RC, Fuzari WMP, Carlotto MS. Meningites bacterianas. Rev Enfermagem e Saúde Coletiva, v. 2, n. 3, p. 40 - 52, 2017.

8. Brunner LS, Suddarth DS. Tratado de enfermagem médico-cirúrgica. Rio de Janeiro: Guanabara Koogan, 2009.

9. Tako KV, Zambianchi P. Influência da hidroterapia em pacientes portadores de sequelas da meningite. Rev UNINGÁ, abr./jun, 2006, n.8, 185-193.

10. DATASUS. Meningite: casos confirmados notificados no sistema de informação de agravos de notificação - sinan net.2015.

11. SUVISA. Situação epidemiológica das meningites na Bahia/ 2015. abr. 2015.

12. Pinheiro P. Meningite - sintomas, causas e tratamento. Portal MD saúde, 2017.

13.CIVES. Centro de Informação em Saúde para Viajantes. 2018.

14. Vranjac A. Meningites virais. Rev Saúde Pública, 2006, 40(4), 748-750.

15.OPAS - Organização Pan-Americana da Saúde. Meningite: Sintomas, Tratamentos e Causas. 2018.

16.Somsri W, Viroj W. Eosinophilic meningitis due to Angiostrongylus cantonensis with confirmed finding of intrathecal parasite. Arquivos de Neuro-Psiquiatria, 2014, 72 (3), 261.

17.Labiak VB, Stocco C, Leite ML, Filho JSV. Aspectos epidemiológicos dos casos de meningite notificados no município de Ponta Grossa - PR, 2001-2005. Cogitare Enferm, 2007 Jul/Set; 12(3):306-12.

18.Paula J, Souza Q, Dias R, Vilela J. Complicações neurológicas e auditivas decorrentes da meningite bacteriana em neonatos. Boa Sorte, BA - 2013.

19.Dazzi MC, Zatti CA, Baldissera R. Perfil dos casos de meningites ocorridas no brasil de 2009 à 2012. Revista UNINGÁ Review. Vol.19,n.3,pp.33-36 (Jul - Set 2014).

20.Lima L, Dantas Q, Andrade EV, Coelho ME, Sena RS. Assistência fisioterapêutica em um hospital de doenças infecciosas: relato de experiência. Anais da Jornada de Fisioterapia da UFC. Fortaleza, 2010; $1(1): 29$

21. Silva APP, Maynard K, Cruz MR. Efeitos da fisioterapia motora em pacientes críticos: revisão de literatura. Rev Bras Ter Intensiva. 2010; 22(1):85-91.

22.Nobre AQTC, Costa IS, Bernardes KO. A fisioterapia no contexto do HIV/AIDS. Fisioter. Mov. 2008 out/dez;21(4):11-18.

23.Magalhães, CBA, Silveira SS, Nogueira ANC, Viana SMNR, Macena RHM. Efetividade da fisioterapia em um paciente pós transplante hepático com diagnóstico de meningite criptocócica: relato de caso. Anais da Jornada de Fisioterapia da UFC. Fortaleza, 2011; 2(1):27

24.Llano JS, Miranda HCFS, Felippe LA, Andrade LP, Silva TCD, Christofoletti G. Investigação dos métodos avaliativos utilizados por fisioterapeutas na especificidade da neurologia funcional. Fisioter Pesq. 2013;20(1):31-36. 
DOI: 10.18606/2318-1419/amazonia.sci.health.v7n3p48-61 Revista Amazônia: Science \& Health

2019, Vol. 7, № 3 .

ISSN: 2318-1419
Silva KCC. Silva JO. Liandro TC.

Atuação fisioterapêutica nos pacientes com sequelas de meningite: Um estudo de revisão.

25.Silva CMS, Castro JCB, Pontes MGS, Venancio RC. A importância da fisioterapia respiratória na unidade de terapia intensiva em recém-nascidos. Revista Conexão Eletrônica. Três Lagoas, MS. 2018, 15 (1), 217224.

26. Kayenne C, Pereira AP, Formiga M. Perfil e características do trabalho dos fisioterapeutas atuantes em unidade de terapia intensiva neonatal. Revista Movimenta. 2010, 3 (2).

27.José A, Pasquero RC, Timbó SR, Carvalhaes SRF, Bien US, Corso SD. Efeitos da fisioterapia no desmame da ventilação mecânica. Fisioter. Mov., Curitiba, 2013, 26 (2), 271-279, abr./jun.

28. Auriema AE, Pereira BFM, Santana PSS. Atuação da fisioterapia em um paciente com quadro agudo de Meningomieloencefalite bacteriana. Revista NovaFisio. 2018.

29. Silveira J, Poletto P, Santos MV. Intervenção Hidroterapêutica Em Paciente Com Paresia De Mmii Por Meningite Tuberculosa e Fúngica. In: Anais da III Mostra de Trabalhos Acadêmicos do Curso de Fisioterapia: CCBS/Univates, 14 de outubro de 2016, Lajeado, RS /Alessandra Kerkhoff, Magali Quevedo Grave, João Alberto Fioravante Tassinary (Orgs.) - Lajeado : Ed. da Univates, 2017.

30.Schmitz FS, Stigger F. Atividades aquáticas em pacientes com paralisia cerebral: um olhar na perspectiva da fisioterapia. Revista de Atenção à Saúde, 2014.

31.Ribas DIR, Israel VL, Manfra EF, Araujo CC. Estudo comparativo dos parâmetros angulares da marcha humana em ambiente aquático e terrestre em indivíduos hígidos adultos jovens. Rev Bras Med Esporte. 2007; 13(6): 371-5.

32. Schneider VFM, Molon C, Rudnicki T, Nicolini-Panisson RDA. Atuação interdisciplinar em um paciente com déficit perceptual: relato de uma experiência. $2^{\circ}$ Congresso de Responsabilidade Socioambiental. Caxias do Sul/RS, junho, 2017. 